\title{
Fabrication of polystyrene/agave particle biocomposites using compression molding technique: evaluation of flammability, biodegradability, mechanical and thermal behaviour
}

\author{
A S SINGHA ${ }^{1, *}$ and RAJ K RANA ${ }^{2}$ \\ ${ }^{1}$ Department of Chemistry, National Institute of Technology, Hamirpur 177 005, India \\ ${ }^{2}$ Department of Chemistry, Chandigarh University, Gharuan, Mohali, India
}

MS received 27 April 2012

\begin{abstract}
Polystyrene (PS) composites reinforced with ungrafted and acrylonitrile (AN) grafted agave particles (AgP) have been prepared with 10-30\% particle content by weight using compression molding technique. The composite specimens thus prepared were subjected to the evaluation of mechanical, chemical, flammability and biodegradability properties. PS composites with $20 \%$ particle loading exhibited optimum mechanical properties. AN grafted AgP/PS composites exhibited higher mechanical strength as compared to ungrafted AgP/PS composites. Further AN grafted AgP/PS composites exhibited better thermal properties and biodegradability as compared to PS matrix. Addition of fire retardant fillers such as magnesium hydroxide $\operatorname{Mg}(\mathrm{OH})_{2}$ and zinc borate lowered burning rate of PS composites considerably. Scanning electron microscopy (SEM) of tensile fracture surfaces of AN grafted AgP/PS composites showed better particle/matrix adhesion.
\end{abstract}

Keywords. Particle; composites; thermal properties; fracture; adhesion.

\section{Introduction}

Natural fibre reinforced polymer composites are in great demand in many applications such as infrastructure development in making products such as door and window frames, marine, sports, automobile, aerospace industry, etc. This is mainly due to increasing environmental concerns and useful properties of natural fibres such as low cost (Holbery and Houston 2006), light weight (Khalid et al 2008), biodegradable nature (Torres and Cubillas 2005), high specific strength (Reis et al 2007), easy processability, etc (Reddy and Yang 2005). Besides a number of advantages, the major limitation of natural fibres is their hydrophilic nature which reduces their compatibility with hydrophobic polymer matrices and ultimately leads to poor fibre/matrix interface. In order to improve the compatibility of natural fibres with polymer matrices, various chemical treatments such as phthalic anhydride coupling (Maldas and Kokta 1990), benzoylation, silane treatment (Girones et al 2007), peroxide treatment (Sapieha et al 1990), graft co-polymerization (Singha and Rana 2010, 2011), mercerization (Gassan and Bledzki 1999; Weyenberg et al 2003), corona discharge treatment (Ragoubi et al 2012), etc have been employed by many workers.

Further the demand for natural fibres as reinforcement in both thermoplastic as well as thermosetting polymer matrices is increasing day by day. However, thermoplastic matrices such as polypropylene (Ragoubi et al 2012), polyethylene (Ahmed and Luyt 2012) and polystyrene (Manikandan

*Author for correspondence (singhaasnit@gmail.com)
Nair et al 2001), etc are much liked among the material scientists as these are recyclable, can be remoulded, offer high impact strength and environmentally much safer as no solvent is used during their processing. Most of the polymer matrix based composites are fabricated by either melt mixing or solution mixing techniques. In melt mixing, the natural fibres are subjected to high shear which results in the damage of fibres. Similarly, in solution mixing technique, the polymer granules are dissolved in the mixture of different organic solvents and then mixed with fibres, which cause various environmental hazards (Joseph et al 1999; Mohanty et al 2002).

An alternative environmental friendly technique is 'hand lay-up method' followed by compression moulding. By hand lay-up method, fibres are evenly spread among alternate layers of polymer resin and then the spaces around the dispersed fibres are filled by polymer resin by compression moulding. This technique has an advantage over the traditional methods like melt mixing or solution mixing as reinforced fibre is not subjected to shear forces and it is more environment friendly as it requires no solvent. Moreover, the samples prepared by compression moulding possess lesser number of voids.

Inspite of many advantages of natural fibre reinforced polymer composites, their use in certain specific applications such as automobile interiors, indoor panels, door and window frames, etc is doubtful as synthetic polymers as well as cellulosic fibres are highly inflammable in nature. The burning rate of natural fibre reinforced polymer composites may be lowered by adding certain fire retardant fillers to them. Several fire retardants such as compounds containing phosphorus, sulphur, antimony, chlorides and bromides are 
used by various workers in fire retardant polymer composites (Zhu and Shi 2003; Sain et al 2004). Halogen containing fire retardants have environmental concerns as they form halogenated dioxins and furans when burnt in accidental fires (Soderstrom and Marklund 2002). The metal hydroxides such as magnesium hydroxides are the most widely accepted fire retardant fillers due to environmental and health safety (Rothom and Horns 1996). Moreover, biodegradability of polymer matrix based composites at their end life cycle is another important requirement which is to be fulfilled before they can be used in the above mentioned applications. Although polymer matrices are not excellent biodegradable materials, however, efforts have been made by many researchers to fabricate partially biodegradable polymer composites by replacing the amount of polymer content by natural biomass (Bharath et al 2010; Chattopadhyay et al 2011).

In the present work, polystyrene composites have been prepared by reinforcing ungrafted and AN-grafted agave particles using compression moulding technique. The objective of the present work is to investigate the effect of AN grafting on the mechanical properties of AgP/PS composites. The effect of addition of magnesium hydroxide and zinc borate has also been investigated on the flammability of AgP/PS composites. Further biodegradability of composite specimens prepared by adding different AgP content (10-30\%wt) has also been studied by soil burial method.

\section{Materials and method}

\subsection{Materials}

Styrene used for the synthesis of PS resin was supplied by acros chemicals. Agave particles used as reinforcement in composites were extracted from the leaves of agave plant in the form of fibres and ground to particle size in electrical grinder (Philips India Ltd.). Acrylonitrile (AN), ceric ammonium nitrate (CAN) and benzoyl peroxide (CDH chemicals), dimethyl formamide (DMF) (E-Merck Germany) were of AR grade.

\subsection{Functionalization of agave particles}

The surface of $\mathrm{AgP}$ was functionalized by graft copolymerization of AN using CAN as initiator. The particles were thoroughly washed with water and dried in hot air oven at $333 \mathrm{~K}$ for $24 \mathrm{~h}$ and finally subjected to the removal of impurities and waxes with acetone in soxhlet apparatus for $72 \mathrm{~h}$. The particles were transferred to the reaction kettle containing $100 \mathrm{~mL}$ of distilled water used as solvent in the grafting reaction. A definite amount of CAN and concentrated nitric acid was added to the reaction mixture which was followed by the addition of definite amount of AN in small fractions with constant stirring. On completion of grafting reaction samples were taken out and homopolymer formed during the reaction was extracted with DMF. The grafted samples were dried in hot air oven at $333 \mathrm{~K}$. The various reaction parameters such as reaction time, temperature, monomer, nitric acid and initiator concentration were optimized (table 1) and graft copolymers prepared under optimum reaction conditions were used as reinforcement for preparation of composites.

\subsection{Synthesis of PS resin}

PS resin was synthesized by free radical polymerization of styrene in presence of benzoyl peroxide as initiator. The reaction mixture was heated to a temperature of $333 \mathrm{~K}$ and the temperature was kept constant till resinification. After resinification, the resin was allowed to cool to room temperature and then transferred to specially made moulds of dimensions $150 \times 150 \times 5 \mathrm{~mm}$. Internal surface of the mould was coated with oleic acid for easy removal of polymer blocks.

\subsection{Fabrication of composites}

The polymer composites were prepared in specially designed moulds of dimensions $150 \times 150 \times 5 \mathrm{~mm}$. Flame retardant fillers were mixed with PS resin with the help of mechanical mixer. Ungrafted as well as grafted $\mathrm{AgP}$ of dimensions $90 \mu$ were spread between five alternate layers of PS resin by hand lay-up method. The moulds were then hot pressed in compression moulding machine at a pressure of $200 \mathrm{~kg} / \mathrm{cm}^{2}$ preheated at a temperature of $353 \mathrm{~K}$. The composites were cured for $12 \mathrm{~h}$ at $373 \mathrm{~K}$.

\subsection{Mechanical properties}

2.5a Tensile strength: The tensile tests were conducted in accordance with ASTM D 3039 on a universal testing machine. The samples of dimensions $100 \times 10 \times 5 \mathrm{~mm}$ were used for analysis. The sample of $100 \mathrm{~mm}$ length was clamped between the jaws of machine with each end covering $20 \mathrm{~mm}$ of sample. The tensile load was applied over $60 \mathrm{~mm}$ span length at a constant strain rate of $10 \mathrm{~mm} / \mathrm{min}$. Tensile load was applied till failure.

2.5b Compressive strength: The compressive test of composite specimens was carried out on computerized universal testing machine in accordance with ASTM D 3410. The test specimen was held between two platforms of the machine and compressive load was applied over $25 \mathrm{~mm}$ span length at a constant strain rate of $10 \mathrm{~mm} / \mathrm{min}$ till failure.

2.5c Flexural strength: The three point bending test was performed in accordance with ASTM D 790 on a universal testing machine. The specimens of dimensions $100 \times$ $10 \times 5 \mathrm{~mm}$ were used for flexural strength analysis. The span length was fixed at $50 \mathrm{~mm}$ and test was conducted at a constant strain rate of $2.54 \mathrm{~mm} / \mathrm{min}$.

2.5d Impact strength: The notched izod impact strength tests were conducted at room temperature in accordance with ASTM D 256 on an impact tester (Tinius Olsen Impact 104). 
Table 1. Optimization of various reaction parameters for grafting of $\mathrm{AN}$ onto Agave americana fibre in air.

\begin{tabular}{|c|c|c|c|c|c|c|c|c|}
\hline $\begin{array}{l}\text { Sr. } \\
\text { No. }\end{array}$ & $\begin{array}{l}\text { Monomer } \\
\left(\mathrm{mol} / \mathrm{l} \times 10^{-1}\right)\end{array}$ & $\begin{array}{l}\mathrm{CAN} \\
\left(\mathrm{mol} / \mathrm{l} \times 10^{-3}\right)\end{array}$ & $\begin{array}{l}\text { Nitric acid } \\
\left(\mathrm{mol} / \mathrm{l} \times 10^{-1}\right)\end{array}$ & $\begin{array}{l}\text { Time } \\
(\min )\end{array}$ & $\begin{array}{l}\text { Temp. } \\
\left({ }^{\circ} \mathrm{C}\right)\end{array}$ & $\% \mathrm{GY}$ & $P_{-\mathrm{e}}$ & $\% \mathrm{Hp}$ \\
\hline 1 & 2.92 & 8.77 & $2 \cdot 77$ & 60 & 25 & 17.9 & $5 \cdot 55$ & 8.66 \\
\hline 2 & 2.92 & 8.77 & 2.77 & 60 & 35 & $18 \cdot 9$ & $5 \cdot 86$ & 9.62 \\
\hline 3 & $2 \cdot 92$ & 8.77 & $2 \cdot 77$ & 60 & 45 & 24 & $7 \cdot 42$ & 42.63 \\
\hline 4 & $2 \cdot 92$ & $8 \cdot 77$ & $2 \cdot 77$ & 60 & 55 & 21.4 & 6.63 & 38.42 \\
\hline 5 & 2.92 & 8.77 & $2 \cdot 77$ & 60 & 65 & $18 \cdot 3$ & 5.68 & $27 \cdot 65$ \\
\hline 6 & 2.92 & 8.77 & 2.77 & 30 & 45 & $16 \cdot 7$ & $5 \cdot 18$ & 24.33 \\
\hline 7 & 2.92 & 8.77 & $2 \cdot 77$ & 90 & 45 & $22 \cdot 4$ & 6.96 & 39.88 \\
\hline 8 & $2 \cdot 92$ & 8.77 & $2 \cdot 77$ & 120 & 45 & $18 \cdot 3$ & 5.68 & 24.04 \\
\hline 9 & $2 \cdot 92$ & $8 \cdot 77$ & $2 \cdot 77$ & 150 & 45 & $16 \cdot 6$ & $5 \cdot 14$ & 23.96 \\
\hline 10 & 2.92 & $4 \cdot 38$ & $2 \cdot 77$ & 60 & 45 & $13 \cdot 5$ & $4 \cdot 19$ & $19 \cdot 15$ \\
\hline 11 & 2.92 & 6.58 & $2 \cdot 77$ & 60 & 45 & $21 \cdot 7$ & $6 \cdot 73$ & 37.55 \\
\hline 12 & 2.92 & $10 \cdot 96$ & $2 \cdot 77$ & 60 & 45 & 22 & 6.86 & $20 \cdot 11$ \\
\hline 13 & 2.92 & $13 \cdot 15$ & $2 \cdot 77$ & 60 & 45 & $16 \cdot 3$ & 5.06 & 18.42 \\
\hline 14 & 2.92 & 8.77 & $1 \cdot 38$ & 60 & 45 & $17 \cdot 7$ & 5.49 & $18 \cdot 10$ \\
\hline 15 & $2 \cdot 92$ & 8.77 & $2 \cdot 07$ & 60 & 45 & $18 \cdot 7$ & $5 \cdot 81$ & 8.78 \\
\hline 16 & 2.92 & 8.77 & 3.46 & 60 & 45 & $12 \cdot 7$ & 3.95 & $14 \cdot 13$ \\
\hline 17 & 2.92 & 8.77 & $4 \cdot 15$ & 60 & 45 & $7 \cdot 6$ & $2 \cdot 34$ & $11 \cdot 21$ \\
\hline 18 & 0.73 & 8.77 & 2.77 & 60 & 45 & 1.9 & 0.61 & $2 \cdot 01$ \\
\hline 19 & 1.46 & 8.77 & 2.77 & 60 & 45 & $2 \cdot 3$ & 0.72 & $2 \cdot 52$ \\
\hline 20 & $2 \cdot 19$ & 8.77 & $2 \cdot 77$ & 60 & 45 & $5 \cdot 6$ & 1.73 & $4 \cdot 21$ \\
\hline 21 & $3 \cdot 65$ & 8.77 & $2 \cdot 77$ & 60 & 45 & $19 \cdot 6$ & 4.86 & $6 \cdot 36$ \\
\hline
\end{tabular}

a

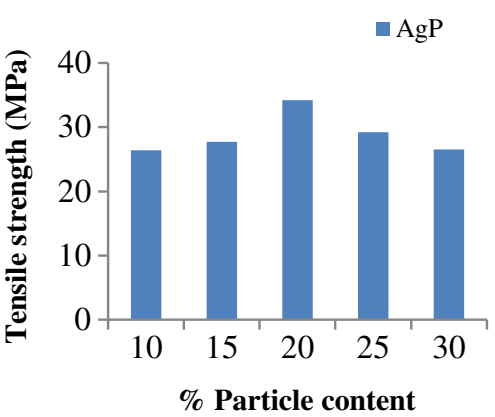

b

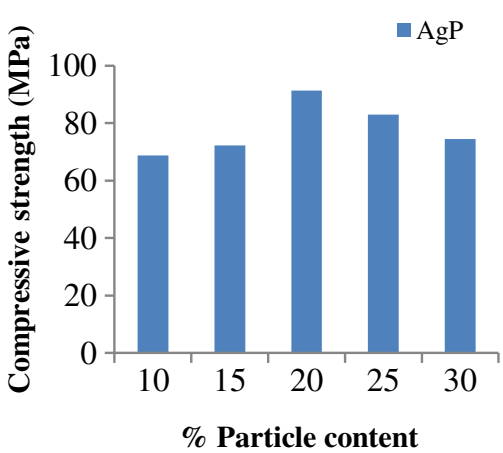

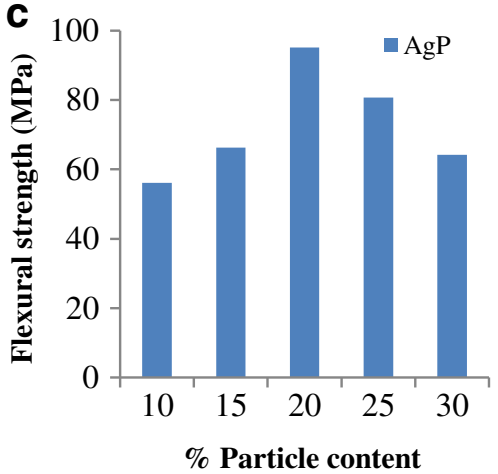

d

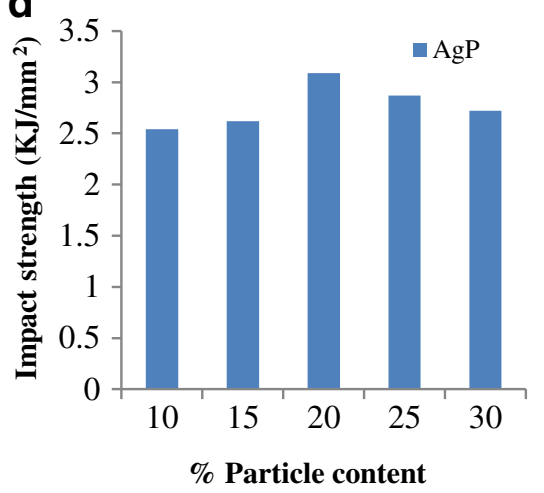

Figure 1. (a-d) Effect of fibre content on mechanical properties of AgP/PS composites. 

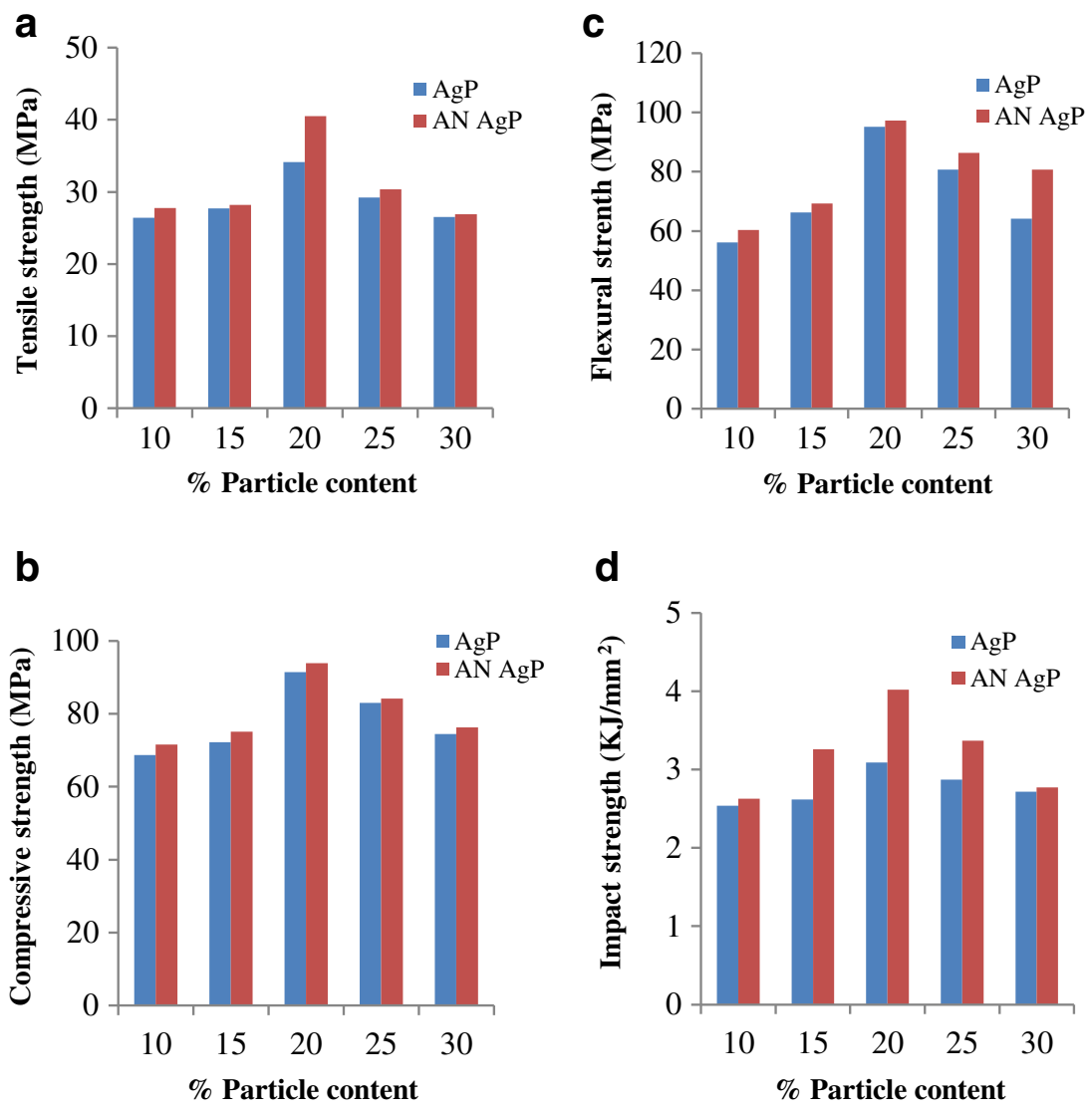

Figure 2. (a-d) Effect of AN grafting on mechanical properties of AgP/PS composites.

The specimens of dimensions $63.5 \times 10 \times 3.5 \mathrm{~mm}$ were used for impact strength analysis. Before testing, a notch was developed on each specimen at an angle of $45^{\circ}$ and $2-2.5 \mathrm{~mm}$ depth. The specimen was clamped in a square support and was struck at the central point by a hemispherical bolt of diameter $5 \mathrm{~mm}$.

\subsection{Chemical resistance}

Chemical resistance studies were performed as a function of percent weight loss upon immersing the composite specimens in $100 \mathrm{~mL}$ of acid $(\mathrm{HCl})$, base $(\mathrm{NaOH})$ and salt $(\mathrm{NaCl})$ of $1 \mathrm{~N}$ strengths. The samples of known weights $\left(W_{1}\right)$ were immersed for a time interval of $720 \mathrm{~h}$. Before taking initial weights, the samples were placed in an hot air oven for $6 \mathrm{~h}$ in order to remove the moisture content. The test samples were taken out and dried till constant weights in hot air oven. The final weights were noted down $\left(W_{2}\right)$ and weight loss percentage was calculated using the following relationship:

$$
\% \text { Weight loss }=\frac{W_{1}-W_{2}}{W_{1}} \times 100 .
$$

\subsection{Flame retardancy}

Flame retardancy studies were carried out by horizontal burning test in accordance with ASTM D635. The specimens of dimensions $125 \times 10 \times 5 \mathrm{~mm}$ were used for these studies.
Two reference points each at 25 and $100 \mathrm{~mm}$ were marked on the specimens from an end. The test specimens were held horizontally and flame was applied at the end. Three replicates of each specimen were used for the studies and average values were reported. The time taken by the flame to reach from the first reference point to the second was recorded and results were reported in terms of rate of burning.

\subsection{Biodegradability}

Biodegradability studies of PS matrix and composites reinforced with ungrafted as well as AN-grafted AgP were carried out by soil burial method. The specimens were buried $50 \mathrm{~cm}$ deep under natural soil in the fields located in Hamirpur town, in the vicinity of the National Institute of Technology for 365 days. The composite specimens were exposed to all weather conditions throughout the year. Before soil burial, the specimens were kept in hot air oven at $353 \mathrm{~K}$ for $12 \mathrm{~h}$ and initial weights $\left(W_{\mathrm{i}}\right)$ were noted. The specimens were evaluated for weight loss after 180 and 365 days. After a definite time interval, the specimens were dug out, washed thoroughly with distilled water and dried in hot air oven at $353 \mathrm{~K}$ for $12 \mathrm{~h}$. The final weights $\left(W_{\mathrm{f}}\right)$ of composites were noted and biodegradability percent was calculated according to the following relationship

$$
\% \text { Biodegradability }=\frac{W_{\mathrm{i}}-W_{\mathrm{f}}}{W_{\mathrm{i}}} \times 100 .
$$



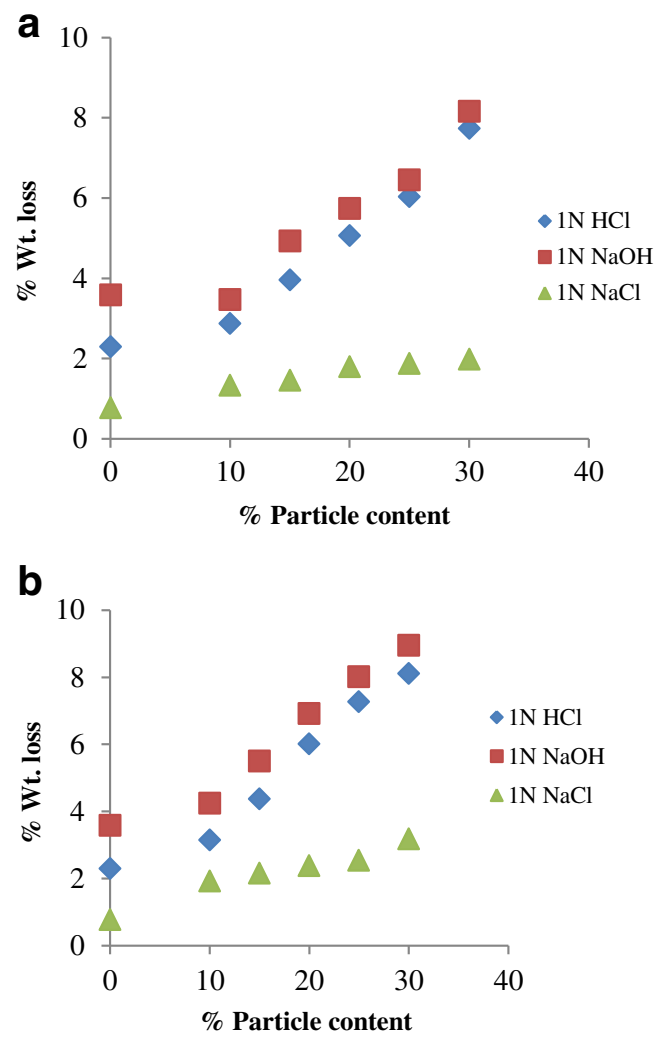

Figure 3. Chemical resistance of (a) ungrafted AgP/PS composites and (b) AN-grafted AgP/PS composites.

\subsection{Fourier transform infrared spectroscopy}

FT-IR spectra of PS matrix and PS composites reinforced with ungrafted and AN grafted $\mathrm{AgP}$ were recorded on Perkin-Elmer infrared spectrophotometer using $\mathrm{KBr}$ pellets (Sigma Aldrich, USA) over a range of $4000-500 \mathrm{~cm}^{-1}$ in order to distinguish chemical changes taking place in PS matrix upon reinforcing ungrafted and AN-grafted AgP.

\subsection{Scanning electron microscopy}

Tensile fractured surfaces of PS resin as well as composites were examined using scanning electron microscopy (SEM) at 1000 times magnification. Scanning electron micrographs were recorded on Leo Electron Microscopy machine (435VP) at an accelerating voltage of $20 \mathrm{kV}$.

\subsection{Thermogravimetric analysis/differential thermal analysis/differential thermal gravimetry}

Thermal behaviours of PS and PS composites were examined by heating composite specimens from room temperature to $1273 \mathrm{~K}$ at a constant heating rate of $283 \mathrm{~K} / \mathrm{min}$ in a thermogravimetric analyser (PerkinElmer).

\section{Results and discussion}

\subsection{Mechanical properties}

3.1a Effect of fibre content: The results of variation of mechanical strength with particle content have been shown in figure 1. It has been observed that mechanical properties of PS matrix increase considerably when reinforced with AgP. Further, mechanical properties also depend upon the particle content in the composites. PS matrix exhibited a tensile strength of $19.90 \mathrm{MPa}$ whereas PS composites exhibited tensile strengths of 26.42, 27.70, 34.16, 29.20 and $26.54 \mathrm{MPa}$ when reinforced with ungrafted $\mathrm{AgP}$ at $10,15,20,25$ and $30 \%$ content by weight, respectively. Similarly, PS matrix exhibited a compressive strength of $52.80 \mathrm{MPa}$, whereas PS composites reinforced with ungrafted $\mathrm{AgP}$ exhibited compressive strengths of 68.74, $72 \cdot 24,91 \cdot 40,82.98$ and $74.42 \mathrm{MPa}$ at 10, 15, 20, 25 and $30 \%$ particle content by weight, respectively.

The flexural strength of neat PS matrix is $34.69 \mathrm{MPa}$ which increases upon reinforcement with ungrafted $\mathrm{AgP}$. Further PS composites reinforced with ungrafted AgP exhibited flexural strengths $56 \cdot 10,66 \cdot 30,95 \cdot 10,80 \cdot 70$ and 64.20 MPa at 10,15,20, 25 and $30 \%$ particle content by weight, respectively. Neat PS matrix exhibited a impact strength of $2.28 \mathrm{~kJ} / \mathrm{mm}^{2}$ PS composites reinforced with ungrafted $\mathrm{AgP}$ exhibited impact strengths of 2.54, 2.62, 3.09, 2.87 and $2.72 \mathrm{~kJ} / \mathrm{mm}^{2}$ at $10,15,20,25$ and $30 \%$ particle content by weight, respectively. It has been observed from the above data that mechanical properties of AgP/PS composites increase initially with increase in particle content up to $20 \%$ and decrease with further increase in particle content beyond $20 \%$ by weight. The initial increase in the mechanical properties can be explained on the basis that with initial increase in particle content, more and more applied load is transferred from matrix onto reinforcement. However, after reaching an optimum value of $20 \%$, further increase in the particle content results in insufficient wetting of agave particles by available PS matrix.

3.1b Effect of AN grafting: Interface has an important role in the transfer of load from matrix onto the reinforcement which influences mechanical properties of the composites. Better the reinforcement/matrix interface, higher will be the mechanical properties of composites.

As a result of AN grafting, the surface of agave particle becomes hydrophobic due to the incorporation of poly (AN) chains. Therefore, AN grafted AgP forms a better interface with PS matrix due to its better compatibility. The effect of AN grafting on mechanical properties of AgP/PS composites is shown in figure 2 .

It has been observed that PS composites exhibited tensile strengths of $27 \cdot 76,28 \cdot 18,40 \cdot 52,30 \cdot 38$ and $26.88 \mathrm{MPa}$; compressive strengths of $71.58,75.06,93.86,84.14$ and 76.32 MPa and flexural strengths of 60.36, 69.30, 97.20, 86.40 and $80.70 \mathrm{MPa}$, when reinforced with AN grafted $\mathrm{AgP}$ at 10, 15, 20, 25 and $30 \%$ particle content, respectively. 
Table 2. Composition and designation of PS composites.

\begin{tabular}{|c|c|c|c|c|c|c|}
\hline Sample designation & $\begin{array}{l}\text { PS } \\
(\% \mathrm{wt})\end{array}$ & $\begin{array}{l}\mathrm{Mg}(\mathrm{OH})_{2} \\
(\% \mathrm{wt})\end{array}$ & $\begin{array}{l}\text { Zinc } \\
\text { borate } \\
(\% \mathrm{wt})\end{array}$ & $\begin{array}{l}\text { Agave } \\
\text { particles } \\
(\% \mathrm{wt})\end{array}$ & $\begin{array}{l}\text { AN- } \\
\text { grafted } \\
(\% \mathrm{wt})\end{array}$ & $\begin{array}{l}\text { Rate of } \\
\text { burning } \\
(\mathrm{mm} / \mathrm{s})\end{array}$ \\
\hline PS & 100 & - & - & - & & $23 \cdot 81$ \\
\hline 30AgP & 70 & - & - & 30 & - & $34 \cdot 40$ \\
\hline $30 \mathrm{AN}$ & 70 & - & - & - & 30 & $21 \cdot 12$ \\
\hline $30 \mathrm{Mg}$ & 70 & 30 & - & - & - & $12 \cdot 40$ \\
\hline $30 \mathrm{ZnB}$ & 70 & - & 30 & - & - & $17 \cdot 16$ \\
\hline $15 \mathrm{Mg} / 15 \mathrm{ZnB}$ & 70 & 15 & 15 & - & - & $17 \cdot 36$ \\
\hline $15 \mathrm{AgP} / 15 \mathrm{Mg}$ & 70 & 15 & - & 15 & - & $14 \cdot 42$ \\
\hline $15 \mathrm{AgP} / 15 \mathrm{ZnB}$ & 70 & - & 15 & 15 & - & $18 \cdot 91$ \\
\hline $10 \mathrm{AgP} / 10 \mathrm{Mg} / 10 \mathrm{ZnB}$ & 70 & 10 & 10 & 10 & - & 17.76 \\
\hline $15 \mathrm{AN} / 15 \mathrm{Mg}$ & 70 & 15 & - & - & 15 & $10 \cdot 80$ \\
\hline $15 \mathrm{AN} / 15 \mathrm{ZnB}$ & 70 & - & 15 & - & 15 & $14 \cdot 90$ \\
\hline
\end{tabular}

Similarly, PS composites reinforced with AN grafted AgP exhibited impact strengths of $2.63,3.26,4.02,3.37$ and $2.77 \mathrm{~kJ} / \mathrm{mm}^{2}$ at $10,15,20,25$ and $30 \%$ particle content. Further, it is clear from the above data that 18.62, 2.69, 2.20 and $30.09 \%$ increase in tensile, compressive, flexural and impact strength has been observed as a result of AN grafting.

\subsection{Chemical resistance}

The results of chemical resistance studies of neat PS matrix and composites reinforced with ungrafted and AN grafted $\mathrm{AgP}$ have been given in figures 3 ( $\mathrm{a}$ and $\mathrm{b}$ ). It is clear from the results that PS composites reinforced with ungrafted as well as AN grafted $\mathrm{AgP}$ exhibited greater weight loss as compared to neat PS matrix. The higher percent weight loss of composites may be explained on the basis that due to the presence of reactive sites on cellulosic particles, they are more vulnerable to the attack of chemicals. Also, it has been observed from the figures that composites exhibited maximum percent weight loss in $\mathrm{NaOH}$ followed by $\mathrm{HCl}$ and $\mathrm{NaCl}$. The maximum percent weight loss in $\mathrm{NaOH}$ may be due to the reason that reactive sites present on agave particles may be more vulnerable to the attack of bases like $\mathrm{NaOH}$. The composites reinforced with $\mathrm{AN}$ grafted $\mathrm{AgP}$ exhibited more stability towards chemicals as compared to the composites reinforced with ungrafted AgP. The higher chemical resistance of AN grafted AgP/PS composites may be explained on the basis that as a result of AN grafting, the reactive sites present on agave particles which are vulnerable to the attack of chemicals may be blocked by grafted poly(AN) chains.

\subsection{Flame retardancy}

The designations of different specimens of PS resins, $\mathrm{AgP} / \mathrm{PS}$ composites and composites reinforced with magnesium hydroxide $\left(\mathrm{Mg}(\mathrm{OH})_{2}\right)$ and zinc borate fillers subjected to flame retardancy tests and the results of studies have been reported in table 2. A considerable decrease in the burning rate has been observed when PS matrix is reinforced with $30 \%$ by wt of AN grafted AgP. However, PS composites reinforced with ungrafted $\mathrm{AgP}$ exhibited higher burning rate as
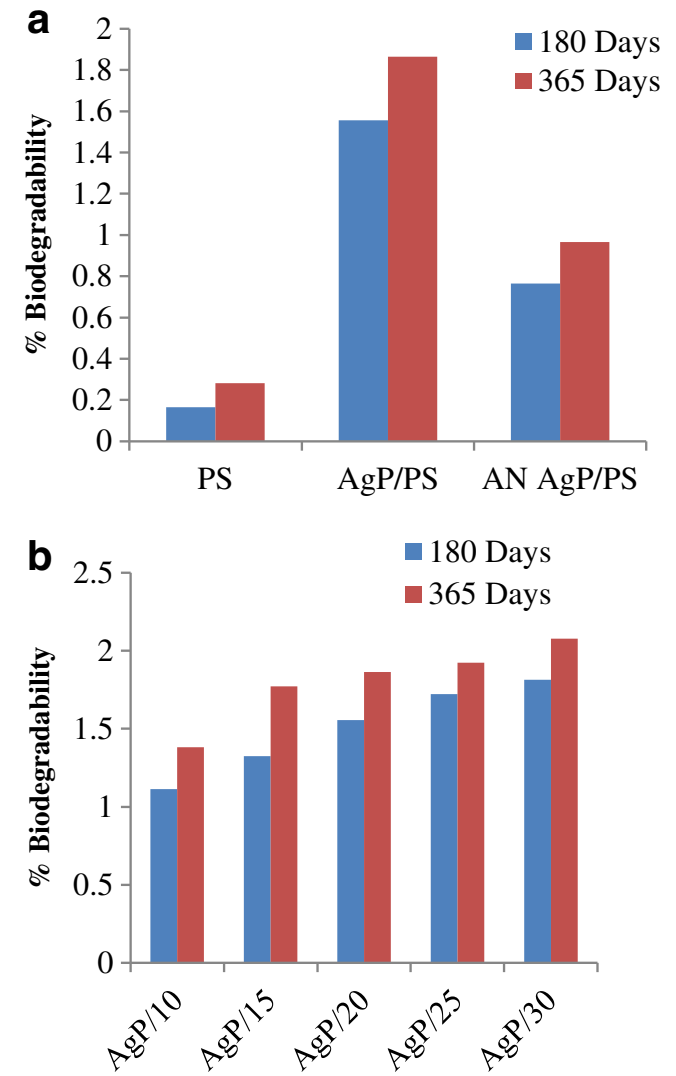

Figure 4. (a) Effect of AN grafting on biodegradability of AgP/PS composites and (b) effect of fibre content on biodegradability of AgP/PS composites.

compared to PS resin. Therefore, it is obvious from these studies that ungrafted agave particles are more flammable as compared to surface modified AgP.

Further, flame retardancy studies indicated that burning rate lowers considerably when PS resin was reinforced with $\mathrm{Mg}(\mathrm{OH})_{2}$ and zinc borate alone, as well as in combination with ungrafted and AN-grafted AgP. Among fire retardant fillers PS matrix reinforced with $\mathrm{Mg}(\mathrm{OH})_{2}$ exhibited lower 


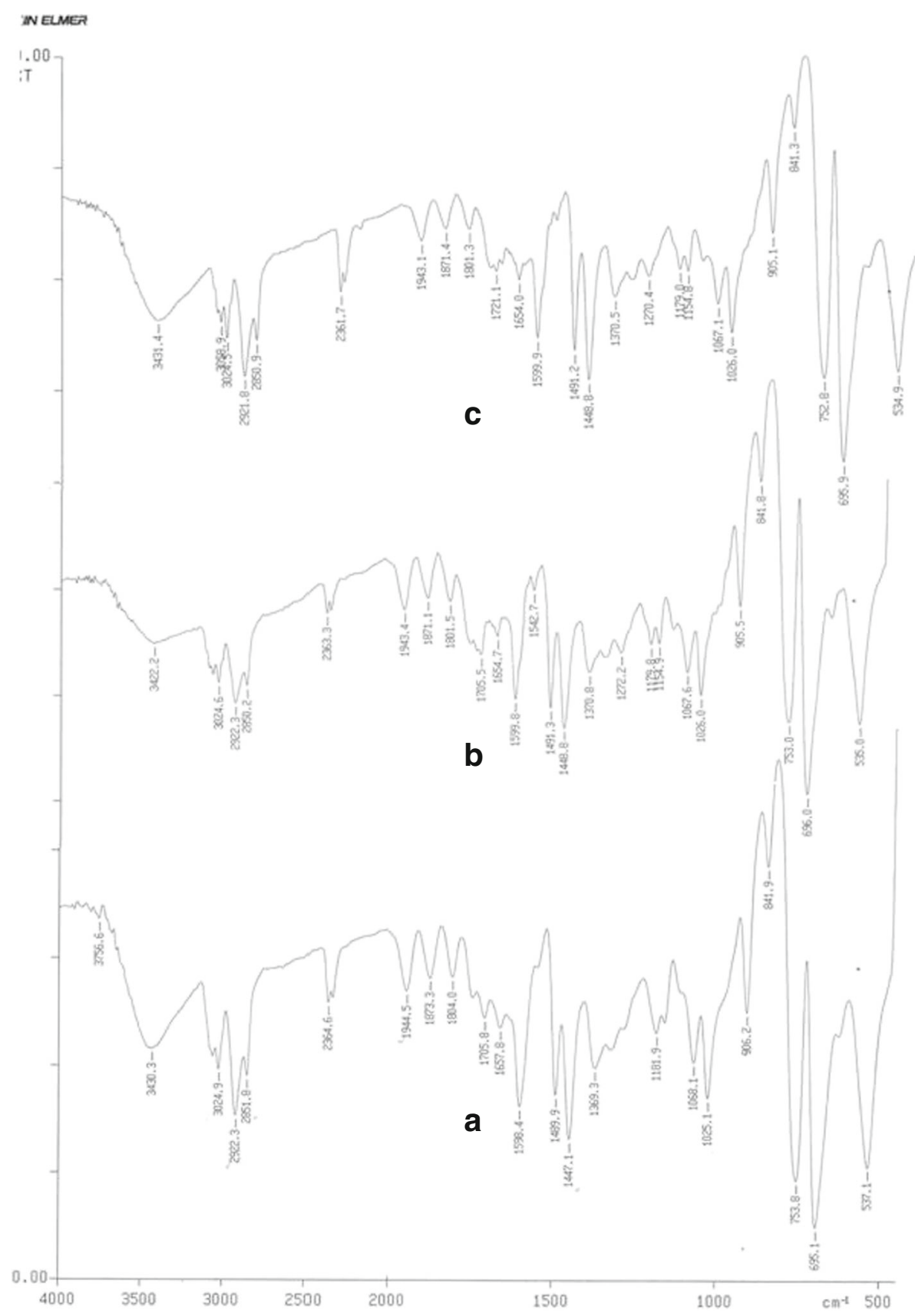

Figure 5. FT-IR spectra of (a) PS matrix and PS composites reinforced with (b) ungrafted and (c) AN-grafted AgP/PS composites.

burning rate as compared to zinc borate showing better flame retardancy of $\mathrm{Mg}(\mathrm{OH})_{2}$ as compared to zinc borate. However, no synergistic effect was observed when $\mathrm{Mg}(\mathrm{OH})_{2}$ and zinc borate were used in combination as burning rate of $15 \mathrm{Mg} / 15 \mathrm{Zn}$ was almost similar to $30 \mathrm{ZnB}$.

However, burning rate further decreased when flame retardant fillers were used in combination with ungrafted and $\mathrm{AN}$ grafted $\mathrm{AgP}$. $15 \mathrm{AgP} / 15 \mathrm{Mg}$ exhibited lowest burning rate among $30 \mathrm{AgP}, 15 \mathrm{AgP} / 15 \mathrm{ZnB}, 15 \mathrm{AgP} / 15 \mathrm{Mg}$ and $\mathrm{PS}$ resin. However, $15 \mathrm{AgP} / 15 \mathrm{Mg}$ composites exhibited higher burning rate as compared to $30 \mathrm{Mg}$. Further, with the addition of flame retardants, i.e. $15 \mathrm{AgP} / 15 \mathrm{Mg}, 15 \mathrm{AgP} / 10 \mathrm{Mg} / 10 \mathrm{ZnB}$,
$15 \mathrm{AgP} / 15 \mathrm{ZnB}$, the burning rate decreased with increasing $\mathrm{Mg}(\mathrm{OH})_{2}$ content. Moreover, a lowest burning rate was observed when $\operatorname{Mg}(\mathrm{OH})_{2}$ was used in combination with AN-grafted AgP. It is clear from the above discussion that poly(AN) chains incorporated on the surface of agave particles due to AN grafting are helpful in decreasing burning rate and show synergism with $\mathrm{Mg}(\mathrm{OH})_{2}$ filler.

\subsection{Biodegradability}

The results of biodegradability studies of PS matrix and composites reinforced with ungrafted and AN-grafted AgP 

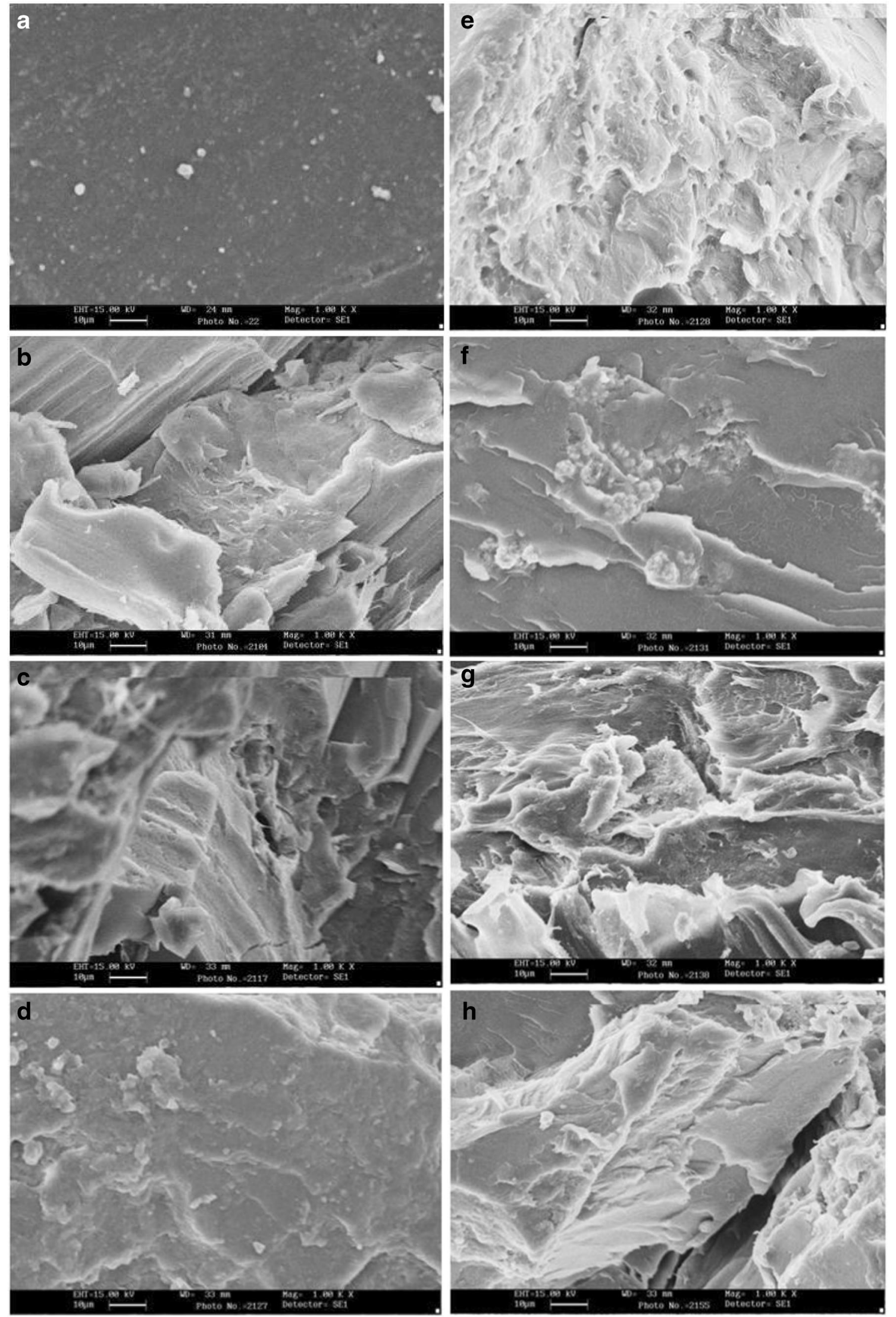

Figure 6. SEM (a) PS matrix, PS composites with (b) $30 \mathrm{AgP}$, (c) $30 \mathrm{AN}$, (d) $30 \mathrm{Mg}$, (e) $30 \mathrm{ZnB}$, (f) $15 \mathrm{Mg} / 15 \mathrm{ZnB}$, (g) $15 \mathrm{AgP} / 15 \mathrm{Mg}$ and (h) $10 \mathrm{AgP} / 10 \mathrm{Mg} / 10 \mathrm{ZnB}$. 
have been shown in figure 4 ( $\mathrm{a}$ and $\mathrm{b}$ ). It has been observed that biodegradability of PS matrix increases when reinforced with both ungrafted as well as AN-grafted AgP. However, AgP/PS composites reinforced with ungrafted particles exhibited more biodegradability as compared to AN grafted particles (figure 4 (a)). The lower biodegradability of ANgrafted AgP/PS composites may be attributed to the development of hydrophobic character on the surface of $\mathrm{AgP}$ as a result of grafting of poly(AN) chains which further results in better particle-matrix adhesion. Therefore, AN-grafted-AgP are better encapsulated by PS matrix and are not exposed to the environmental degradation as compared to ungrafted AgP.

Further an increase in biodegradability has been observed with the increase in particle content in composites which may be expected due to increase in the amount of biodegradable component (AgP) as compared to PS matrix (figure 4 (b)).

\subsection{Evidence of reinforcement by FT-IR spectroscopy}

The reinforcement of ungrafted and AN grafted agave particles in PS matrix was confirmed from the following data of FT-IR analysis. FT-IR spectra of PS matrix, ungrafted and AN-grafted AgP/PS composites have been represented in figures $5(\mathrm{a}-\mathrm{c})$.

PS Matrix: $537 \cdot 1 \mathrm{~cm}^{-1}=$ out of plane bending of phenyl ring; $695.1 \mathrm{~cm}^{-1}=$ out of plane bending of $\mathrm{C}-\mathrm{H}$ of benzene ring; $753.8 \mathrm{~cm}^{-1}=\mathrm{C}-\mathrm{C}$ deformation in mono substituted benzene ring; $906.2 \mathrm{~cm}^{-1}=$ aromatic $\mathrm{C}-\mathrm{H}$ stretching; $1447.1,1489.9$ and $1598.4 \mathrm{~cm}^{-1}=\mathrm{C}=\mathrm{C}$ stretching in benzene ring; $2851.8 \mathrm{~cm}^{-1}=$ symmetric $\mathrm{C}-\mathrm{H}$ stretching in $\mathrm{CH}_{2}$; $2922.3 \mathrm{~cm}^{-1}=$ asymmetric $\mathrm{C}-\mathrm{H}$ stretching in $\mathrm{CH}_{2} ; 3024.9$, $3060 \mathrm{~cm}^{-1}=\mathrm{C}-\mathrm{H}$ stretching of benzene ring.

Ungrafted AgP/PS composites: $1271.0 \mathrm{~cm}^{-1}=\mathrm{C}-\mathrm{O}-\mathrm{C}$ and $\mathrm{C}=\mathrm{O}$ stretching in xylan side substituent and lignin aromatic $\mathrm{C}=\mathrm{O}$ stretching; $1654.0 \mathrm{~cm}^{-1}=\mathrm{H}-\mathrm{O}-\mathrm{H}$ bending of absorbed water and $\mathrm{C}-\mathrm{H}$ deformation of lignin; $3432.5 \mathrm{~cm}^{-1}=\mathrm{O}-\mathrm{H}$ stretching of $\mathrm{H}$-bonded groups.

AN-grafted AgP/PS composites: $2245 \cdot 3 \mathrm{~cm}^{-1}=-\mathrm{C} \equiv \mathrm{N}$ group of AN.

\subsection{Scanning electron microscopy}

Scanning electron micrographs of PS matrix, tensile fractured composites reinforced with ungrafted, AN-grafted $\mathrm{AgP}$ and fire retardant fillers have been shown in figure 6 $(\mathrm{a}-\mathrm{h})$. From SEM studies a clear cut change in the morphology of PS matrix has been observed when reinforced with ungrafted, $\mathrm{AN}$-grafted $\mathrm{AgP}$ and fire retardant fillers. In case of composites reinforced with AN-grafted AgP, uniform mixing of the particles with matrix has been observed. In figures 6 (d-e) a good distribution of $\mathrm{Mg}(\mathrm{OH})_{2}$ and zinc borate in PS matrix was observed and rough fracture surface was noticed. a

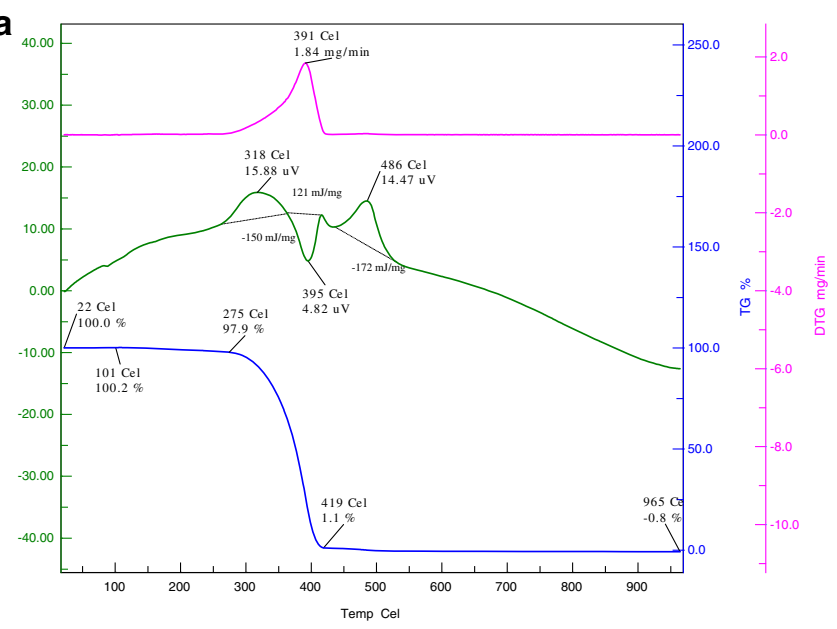

b

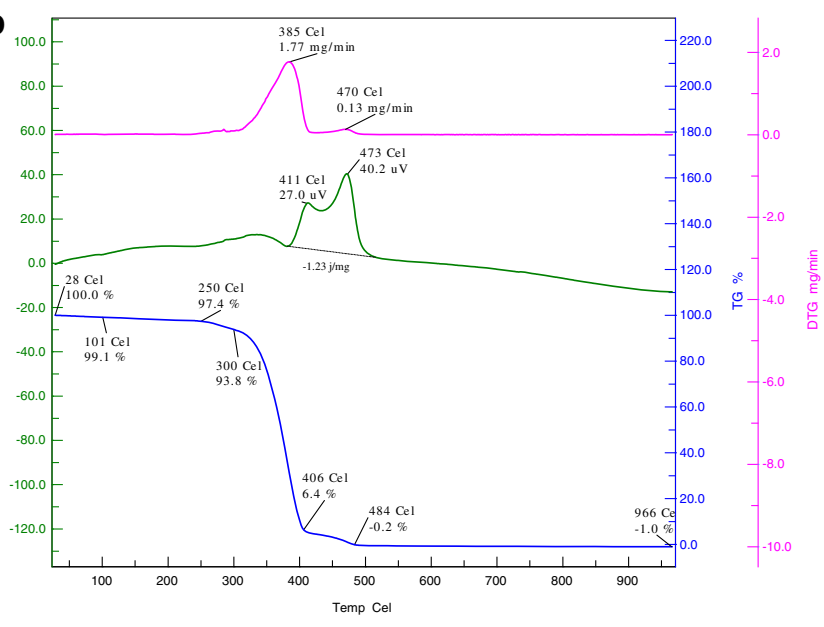

C

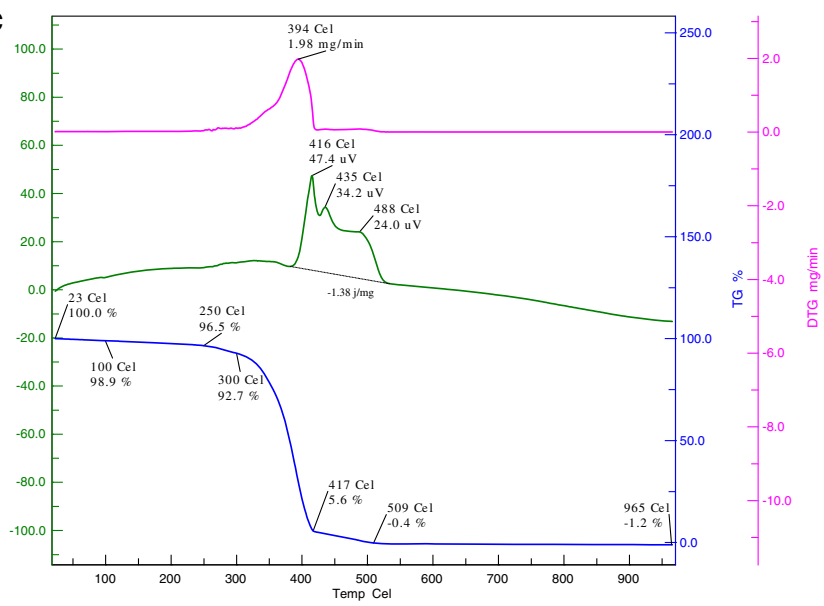

Figure 7. Thermograms of (a) PS matrix, (b) ungrafted AgP/PS composites and (c) AN-grafted Ag and AgP/PS composites.

\subsection{Thermal characterization by TGA/DTA/DTG}

The initial decomposition temperature (IDT) and final decomposition temperature (FDT) of PS matrix has been found to be 295 and $419{ }^{\circ} \mathrm{C}$, respectively. DTA curve of PS matrix exhibited exothermic/endothermic peaks at $318{ }^{\circ} \mathrm{C}$ $(15.88 \mu \mathrm{V}), 395^{\circ} \mathrm{C}(4.82 \mu \mathrm{V}), 486{ }^{\circ} \mathrm{C}(14.47 \mu \mathrm{V})$. Further 
in DTG curve exothermic peak has been observed at $391{ }^{\circ} \mathrm{C}$ with a weight loss of $1.84 \mathrm{mg} / \mathrm{min}$.

IDT of ungrafted AgP/PS composites (20\% wt) has been found to be $310{ }^{\circ} \mathrm{C}$ whereas FDT is $484{ }^{\circ} \mathrm{C}$. Similarly, IDT of AN-grafted AgP/PS composites has been found to be $316{ }^{\circ} \mathrm{C}$ and FDT has been found to be $509{ }^{\circ} \mathrm{C}$. DTA curves of PS composites reinforced with ungrafted $\mathrm{AgP}$ exhibited exothermic peaks at $411{ }^{\circ} \mathrm{C}(27.0 \mu \mathrm{V}), 473{ }^{\circ} \mathrm{C}$ $(40 \cdot 2 \mu \mathrm{V})$ and composites reinforced with AN-grafted AgP exhibited exothermic peaks at $416{ }^{\circ} \mathrm{C}(47.4 \mu \mathrm{V}), 488{ }^{\circ} \mathrm{C}$ $(24.0 \mu \mathrm{V})$. DTG curves of ungrafted AgP/PS composites exhibited exothermic peaks at $385{ }^{\circ} \mathrm{C}$ with a weight loss of $1.77 \mathrm{mg} / \mathrm{min}$ and AN-grafted AgP/PS composites exhibited exothermic peaks at $394{ }^{\circ} \mathrm{C}$ with a weight loss of $1.98 \mathrm{mg} / \mathrm{min}$.

It has been observed from the above data that PS composites reinforced with ungrafted as well as $\mathrm{AN}$ grafted AgP show higher thermal stability as compared to PS matrix. Further AN-grafted AgP/PS composites have higher decomposition temperature (DT) as compared to ungrafted AgP/PS composites. The higher DT of composites reinforced with grafted fibres may be attributed to better fibre/matrix adhesion which increases thermal stability. Thermograms of PS matrix and ungrafted and AN-grafted AgP/PS composites have been shown in figure $7(\mathrm{a}-\mathrm{c})$.

\section{Conclusions}

Grafting of agave particles with acrylonitrile increases the compatibility and hence improves particle-matrix adhesion which leads to enhancement in the mechanical properties of PS matrix as well as ungrafted AgP/PS composites. Further composites reinforced with grafted AgP show more resistance to the attack of chemicals. Both ungrafted and ANgrafted AgP/PS composites exhibited higher biodegradability as compared to PS matrix. Burning rate was considerably lowered when flame retardants were used in combination with AN-grafted AgP. However, no synergistic effect has been observed between $\mathrm{Mg}(\mathrm{OH})_{2}$ and zinc borate fillers.

\section{Acknowledgements}

Authors are highly thankful to the Director, National Institute of Technology, Hamirpur, for providing necessary laboratory facilities to complete this work and MHRD, New Delhi for financial assistance during the course of this work.

\section{References}

Ahmed E E M and Luyt A S 2012 Compos. Part. A. 43703

Bharath K N, Swamy R P and Mohan Kumar G C 2010 Int. J. Agri. Sci. 21

Chattopadhyay S K, Singh S, Pramanik N, Niyogi U K, Khandal R K, Uppaluri R and Ghoshal A K 2011 J. Appl. Polym. Sci. 121 2226

Gassan J and Bledzki A K 1999 Compos. Sci. Technol. 591303

Girones J, Mendez J A, Boufi S, Vilaseca F and Mutje P 2007 J. Appl. Polym. Sci. 1033706

Holbery J and Houston D 2006 Min. Met. Mat. S. 5880

Joseph P V, Joseph K and Thomas S 1999 Compos. Sci. Technol. 591625

Khalid M, Ratnam C T, Chuah T G, Ali S and Choong T S Y 2008 Mat. Des. 29173

Maldas D and Kokta B V 1990 J. Appl. Polym. Sci. 41185

Manikandan Nair K C, Thomas S and Groeninckx G 2001 Compos. Sci. Technol. 612519

Mohanty A K, Drzal L T and Misra M 2002 J. Adhes. Sci. Technol. 16999

Ragoubi M, George B, Molina S, Bienaime D, Merlin A, Hiver J M and Dahoun A 2012 Compos. Part. A. 43675

Reddy N and Yang Y 2005 Trends Biotechnol. 2322

Reis P N B, Ferreira J A M, Antunes F V and Costa J D M 2007 Compos. Part A. 381612

Rothom R N and Horns P R 1996 Polym. Degrad. Stabil. 54383

Sain M, Park S H, Suhara F and Law S 2004 Polym. Degrad. Stabil. 83363

Sapieha S, Allard P and Zang Y H 1990 J. Appl. Polym. Sci. 41 2039

Singha A S and Rana R K 2010 Adv. Mat. Let. 1156

Singha A S and Rana R K 2011 Int. J. Poly. Mat. 60729

Soderstrom G and Marklund S 2002 E.S. \& T. 361959

Torres F G and Cubillas M L 2005 Polym. Test 24694

Weyenberg V, Ivens I, Coster J, Kino A, Baetens B and Verpoest E 2003 Compos. Sci. Technol. 631241

Zhu S and Shi W 2003 Polym. Degrad. Stabil. 80217 